\title{
Deficient Social and Play Behavior in Juvenile and Adult Rats after Neonatal Cortical Lesion: Effects of Chronic Pubertal Cannabinoid Treatment
}

\author{
Miriam Schneider*,' and Michael Koch' \\ 'Department of Neuropharmacology, Brain Research Institute, University of Bremen, Bremen, Germany
}

\begin{abstract}
The aim of the present study was to investigate the effects of neonatal excitotoxic lesions of the medial prefrontal cortex (mPFC) on social play, social behavior unrelated to play, and self-grooming in juvenile and adult rats. We additionally examined the behavioral effects of chronic pubertal treatment with the cannabinoid agonist WIN 55,212-2 (WIN) in order to test the hypothesis that early lesions render the brain vulnerable to cannabinoid intake in later life. Neonatal mPFC lesions and pubertal WIN treatment disrupted social play, social behavior, and self-grooming in juvenile and adult rats. Additionally, we observed more social play behaviors during light cycle in WIN-treated than in vehicle-treated rats. Notably, the combination of surgery and WIN treatment disrupted social behavior in lesioned and sham-lesioned rats. The present data indicate that the mPFC is important for adequate juvenile response selection in the context of social play and might be involved in the development of adult social and nonsocial behavior. Moreover, our data add further evidence for an involvement of the cannabinoid system in anxiety and social behavior. Additive effects of neonatal surgery-induced stress or cortical lesions in combination with pubertal cannabinoid administration are also shown. The disturbances of social and nonsocial behavior in rats are comparable to symptoms of early frontal cortex damage, as well as neurodevelopmental disorders in humans, such as schizophrenia and autism. Therefore, we propose the combination of neonatal cortical lesions with chronic cannabinoid administration during puberty as an animal model for studying neuronal mechanisms of impaired social functioning in neuropsychiatric disorders.

Neuropsychopharmacology (2005) 30, 944-957, advance online publication, 8 December 2004; doi: I0.1038/sj.npp. 1300634
\end{abstract}

Keywords: WIN 55,212-2; play fighting; prefrontal cortex; puberty; social behavior; neurodevelopmental disorders

\section{INTRODUCTION}

Early prefrontocortical damage in humans has been shown to impair cooperative and reciprocal behavior, social interactions, and social cognition (Eslinger et al, 2004; Anderson et al, 1999). Inadequate social behavior is also a notable characteristic of neurodevelopmental psychiatric disorders, including schizophrenia and autism. Social withdrawal and isolation are key components of the negative symptoms of schizophrenia. The core symptoms of autism include specific impairments of reciprocal social relationships, cooperative play with peers, and impoverished or atypical social behavior (DSM IV, American Psychiatric Association, 1994; Waterhouse et al, 1996; Grossman et al, 1997). Adult animals that have sustained neonatal lesions are increasingly recognized as useful

*Correspondence: Dr M Schneider, Department of Neuropharmacology, Brain Research Institute, University of Bremen, PO Box 3304 40, Bremen 28334, Germany, Fax: + 4904212184932 ,

E-mail: miriam.schneider@uni-bremen.de

Received 10 June 2004; revised I November 2004; accepted 3 November 2004

Online publication: II April 2004 at http://www.acnp.org/citations/ NPPI I 0404040267/default.pdf models to study neurodevelopmental deficits underlying neuropsychiatric disorders (eg Lipska et al, 1995, 2002a, b; Flores et al, 1996). It is well known that dysfunctions and morphological abnormalities of the prefrontal cortex (PFC) are strongly implicated in the pathophysiology of schizophrenia (Benes et al, 2000; Selemon, 2001; Weinberger and Lipska, 1995) and are also involved in autism (Baron-Cohen et al, 1999; Mundy, 2003; Luna et al, 2002). It has been shown that neonatal lesions of the PFC alter cortical structure, connectivity, and behavior differently than do PFC lesions in adult animals (Kolb and Whishaw, 1985; Kolb et al, 1987; Flores et al, 1996; Bennay et al, 2004; Schwabe et al, 2004). Therefore, neonatal PFC lesions have been proposed as an adequate model to investigate early developmental aberrations (Flores et al, 1996; Bennay et al, 2004).

In addition to early neurodevelopmental processes, the ontogenetic transition from youth to adulthood is a critical developmental period. Puberty is accompanied by maturational processes in the medial PFC (mPFC) and limbic regions (Spear, 2000), which are characterized by both progressive and regressive changes, such as myelination and synaptic pruning (De Bellis et al, 2001). Furthermore, maturation of neurotransmitter systems such as the 
glutamatergic, the dopaminergic, and also the endogenous cannabinoid system occur during this period (Spear, 2000; Rodriguez de Fonseca et al, 1993). These maturational processes are necessary for the occurrence of adult behavioral performance and are vulnerable to the adverse effects of drugs (Chambers et al, 2003). A recent study reported different effects on social play and social behavior after acute ethanol administration in adolescent and adult rats (Varlinskaya and Spear, 2002). We have previously shown that chronic pubertal administration of the synthetic cannabinoid agonist WIN 55,212-2 (WIN) leads to more severe and long-lasting behavioral disturbances in adulthood than a comparable treatment of adult rats (Schneider and Koch, 2003). These findings are in accordance with other studies finding similar effects in humans (Ehrenreich et al, 1999; Pope et al, 2003) and rodents (Stiglick and Kalant, 1985). Moreover, there is growing evidence for an association between pubertal cannabis consumption and subsequent risk of developing schizophrenia (van Os et al, 2002; Arseneault et al, 2002, 2004; Zammit et al, 2002).

Social play behavior is an activity common to juveniles of many mammalian and avian species (Fagen, 1981) and is a complex and early form of (nonmother-directed) social behavior (Pellis and Pellis, 1998; Vanderschuren et al, 1997). Social play has a considerable incentive value (Vanderschuren et al, 1997, 1995) and is important for the development of social skills and the selection of appropriate behavioral patterns (Vanderschuren et al, 1997). Since play fighting is most obvious in mammals, it was suggested that social play is positively correlated with encephalization (Fagen, 1981) and depends upon distinct specializations of the mammalian brain such as a highly evolved neocortex (Panksepp et al, 1994). Surprisingly, it was found that neonatally decorticated rodents still engage in play fights as juveniles (Panksepp et al, 1994; Pellis et al, 1992). These findings indicate that an intact cortex is not necessary for rats to engage in social play and, therefore, cannot be involved in the motivation of social play behavior (Pellis et al, 1992). However, decorticated rats showed a significant reduction in pinning, a common position in play fights in which one rat stands over a supine partner. By itself, pinning is an insufficient measure for investigating the mechanisms of an altered frequency of social play, since most pins arise from combined action of two play partners, where one attacks and the other adopts a particular defensive position (Pellis et al, 1992). A thorough study by Pellis et al (1992) showed that the reduced pinning frequency in decorticated rats reflects an altered pattern of defense, rather than a reduction in play fighting.

Social play and social behaviors unrelated to play differ particularly in their ontogenetic processes (Vanderschuren et al, 1995). The onset of play fighting begins at about 18 days postnatally (Pellis and Pellis, 1997). This behavior is shown most frequently between day 30 and 40 and decreases in puberty, but does never disappear completely, whereas social behaviors unrelated to play in rats remain constant over the whole lifespan (Vanderschuren et al, 1995).

Therefore, the present study investigated the effects of neonatal excitotoxic mPFC lesions on play fighting, social behavior unrelated to play, and self-grooming in juvenile and adult rats. Motivational aspects of adult social behavior were determined by means of a conditioned place preference (CPP) test (Van den Berg et al, 1999). Furthermore, the effects of chronic pubertal WIN treatment in combination with neonatal lesions on adult rats' behavior was also tested.

\section{METHODS}

\section{Subjects}

In all, 71 naïve male first-generation offspring Wistar (Hannover) rats from our breeding colony were used for this study. Adult male and female Wistar (Hannover) rats were purchased from Harlan-Winkelmann (Borchen, Germany) and housed together in pairs under standard conditions in Macrolon cages (Type IV) on a $12 \mathrm{~h}$ light-dark schedule (lights on 0700-1900). They had free access to tap water and were fed ad libitum. The litters were culled to eight pups immediately after birth (all male if possible). In order to avoid litter effects, equal proportions of rats of each litter were assigned to the different treatment groups. After weaning on postnatal day (pd) 21, male pups were housed in a different room in groups of three to six in Macrolon cages (Type IV) under standard conditions on a $12 \mathrm{~h}$ lightdark schedule (lights on 0700-1900). They received free access to tap water and were fed ad libitum until pd 40 after reaching a body weight of $180 \mathrm{~g}$. Then, they were maintained on a body weight of $250-300 \mathrm{~g}$ by controlled feeding of $12 \mathrm{~g}$ rodent chow/rat/day.

The experiments were carried out in accordance with the $\mathrm{NIH}$ ethical guidelines for the care and use of laboratory animals for experiments, and were approved by the local animal care committee.

\section{Drugs}

WIN (Sigma-Aldrich, Germany) was dissolved in $0.1 \%$ Tween 80 and diluted in saline $(0.9 \% \mathrm{NaCl})$. The drug was administered intraperitoneally (i.p.) at a dose of $1.2 \mathrm{mg} / \mathrm{kg}$. Ibotenic acid (Sigma-Aldrich, Germany) was dissolved in $0.1 \mathrm{M}$ phosphate-buffered saline (PBS). For neonatal lesions, $2 \mu \mathrm{g} / 0.3 \mu \mathrm{l}$ ibotenic acid was administered bilaterally (see surgery). The experimenter was not aware of the drug or surgery treatment of the animals during behavioral testing.

\section{Experimental Procedure}

Rat pups were randomly assigned to lesion, sham-lesioned, or naïve control groups on pd 7. Surgery took place on pd 7 and the animals were left undisturbed afterwards until weaning on pd 21. Prepubertal behavioral testing (social behavior, play behavior, and locomotor activity) took place between pd 30 and 35 . The peripubertal chronic treatment with WIN or vehicle lasted 25 days from pd 40 to 65 (throughout the rats' puberty). During this period of time, the rats received 20 injections i.p., which were not delivered regularly. The rats received either 1,2 , or no injection each day (10 times one injection, five times two injections, and 10 times no injection per day) (Schneider and Koch, 2003). This protocol was chosen in order to mimic the irregular consumption practice in humans (Lamarque et al, 2001). Adult rats were tested again for play behavior and social 
behavior between pd 80 and 85 . Behavioral testing in an open field took place on pd 80 and CPP for social contact was tested between pd 90 and 100 .

\section{Surgery}

Animals that were randomly assigned to lesion or shamlesioned groups were anesthetized by hypothermia on pd 7, which was achieved by placing the pups on ice for 15$20 \mathrm{~min}$. Rats were then fixed in a stereotaxic apparatus (TSE, Bad Homburg, Germany) with atraumatic ear bars and snout holder for small animals. Ibotenic acid $(2 \mu \mathrm{g} /$ $0.3 \mu \mathrm{l})$ was infused bilaterally over a period of $180 \mathrm{~s}(0.02 \mu \mathrm{l} /$ $12 \mathrm{~s}$ ) using a microliter syringe ( $\mathrm{SGE}$, Germany $\mathrm{GmbH}$ ) into the $\mathrm{mPFC}(2.5 \mathrm{~mm}$ rostral, $\pm 0.3 \mathrm{~mm}$ lateral, and $3.3 \mathrm{~mm}$ ventral to bregma). Stereotoaxic coordinates were based on pilot studies and the Atlas from Sherwood and Timiras (1970). Sham-lesioned rats received an equal volume of PBS. The needle was left in place $1 \mathrm{~min}$ before the injection of ibotenic acid/PBS and $5 \mathrm{~min}$ after infusion in order to prevent back flow of neurotoxin through the needle track. After surgery, wounds were closed with medical adhesive and the rats were put on an electrical heating pad before being returned to their mother.

\section{Behavioral Testing}

Play fighting, social behavior unrelated to play, and selfgrooming. One aim of the present study was to investigate the spontaneous occurrence of play, social behavior, and self-grooming and its possible disturbances after neonatal lesions and chronic cannabinoid exposure. Therefore, the animals were not isolated before videotaping, a common method that is used to induce an enhanced frequency of playful activities in other studies. All animals were videotaped in their homecages for recording play behavior and social activities in a group of pairmates. Rats were divided in groups of three (one lesion, one sham-lesioned, and one control animal). All groups were tested in their homecages in the prepubescent period, between day 30 and 35 , and in the postpubescent period after reaching sexual maturity, between day 80 and 85 . After prepubertal testing, half of the groups received the chronic WIN administration, whereas the others received vehicle. Tests were conducted for $2 \mathrm{~h}$ between 1800 and 2000 . The first hour of recording started in the light half of the animals' cycle and the second hour took place in the dark half (under $60 \mathrm{~W}$ red light). For videotaping, a panasonic camcorder was used. Several behavioral elements were quantified, which are discussed below.

Play behavior: Beside the frequency of play behaviors (pins, attacks, and defensive behavior) (Pellis et al, 1992; Pellis and McKenna, 1995; Pellis and Pellis, 1997), the percentage of defensive behavior depending upon the number of attacks received was also evaluated (see Defense). We further analyzed the percentage of pins for an animal, initiated by its own complete rotation and also the probability to respond upon an attack. Additionally, the number of play behaviors (pinning, attacks initiated, and attacks received) that occurred during light phase were scored and evaluated as the percentage of the total number of play that appeared during light and dark. During the light phase, only pins and attacks were scored as markers for play behavior, since only few play fights occurred during this phase:

(1) Pins: One animal is lying on its back with the partner standing over him. Since both animals are involved actively in this behavior pinning was counted for both of them.

(2) Attacks: One animal brings the tip of his snout either in contact with or very close to the nape of its playpartner.

(3) Defense: Withdrawal of the nape area by a rat upon attack. Since different rats attacked at different frequencies, the number of defensive responses by each rat depended on the number of attacks received. Therefore, the rate of defense was also expressed as the percentage of the total number of attacks received (Pellis et al, 1992). (a) Evade: The recipient runs, leaps, or swerves away and moves his face away from the attacker. (b) Facing defense: The recipient withdraws his nape from an attacker, but in doing so turns around and faces his partner. Facing defense typically involves one of three types of tactics: (I) Complete rotation: Upon contact the recipient rotates around 1st longitudinal axis, cephalocaudally, to a supine position. (II) Partial rotation: Upon contact, the recipient rotates around its longitudinal axis, cephalocaudally, but stops at the pelvis, and maintains a standing position on its hind feet. (III) Others: Upon contact, the recipient adopts some alternative strategies such as standing upright or turning toward the partner while remaining prone. These forms of facing defense were only scored if they did not ensue from a previous partial rotation.

Social behavior: Contact behavior, social investigation, and tail manipulation were scored as social behaviors (Vanderschuren et al, 1995; Pellis and Pellis, 1997):

(1) Contact behavior: Contact behavior includes (a) grooming (chewing and licking the partner's fur) and (b) crawling over the partner.

(2) Social investigation: Sniffing at any part of the partner's body, mainly the anogenital area.

(3) Tail manipulation: Grabbing, biting, and pulling the partners tail (mainly seen in juvenile rats).

Self-grooming behavior: Licking or biting their own fur and rubbing the forepaws over the head (Robertson et al, 1999).

CPP for social contact. Place preference conditioning took place in a plastic box $\left(25 \times 84 \times 33 \mathrm{~cm}^{3}\right)$, which consisted of three different compartments. The two larger test compartments were separated through a white start box $\left(25 \times 13 \times 33 \mathrm{~cm}^{3}\right)$. Test compartment $1\left(25 \times 28.5 \times 33 \mathrm{~cm}^{3}\right)$ had a rough floor and wide black stripes on the wall. This compartment was used for free interaction with the social partner. The second compartment $\left(25 \times 42.5 \times 33 \mathrm{~cm}^{3}\right)$ had a smooth floor and thin black stripes on the wall. In this compartment, a small area $\left(25 \times 14 \times 33 \mathrm{~cm}^{3}\right)$ could be separated by a glass panel. Behind this panel, the social 
partner was placed as a nonsocial stimulus. Each experiment was carried out over 7 days and was divided into (I) preconditioning phase, (II) conditioning phase, and (III) postconditioning phase (Van den Berg et al, 1999). On day 1 , all rats were acclimatized to the test box for $10 \mathrm{~min}$ where they had free access to all three compartments. On the following day, the initial place preference (time the animals spent in the three different compartments, respectively) was measured for $10 \mathrm{~min}$ for all groups. Afterwards, all test animals were isolated in small Macrolon cages where they stayed until the following test period. The conditioning apparatus has been designed such that naïve animals do not show an initial preference for either of conditioning compartments upon the first exposure, allowing for unbiased tests (Cheer et al, 2000). The conditioning phase consisted of four training days, each including two $10 \mathrm{~min}$ sessions. First, the rat was placed in compartment 2 with a nonsocial stimulus (social partner behind the glass panel), and directly afterwards, the rat was placed in compartment 1 where it could freely interact with a social partner. During conditioning, the compartments were closed to restrict exploration of the box. In the postconditioning phase (place preference test), which followed directly after the last training day, the rats had free access to all three compartments for $10 \mathrm{~min}$ and the time spent in each compartment was recorded.

Since a 4-day period of social isolation was necessary for the experiment, only adult rats were tested for CPP.

Open field. Locomotor activity was measured in an infrared-beam-operated open field $\left(44.7 \times 44.7 \times 44 \mathrm{~cm}^{3}\right.$, ActiMot-System, TSE, Bad Homburg, Germany) for $35 \mathrm{~min}$. At the beginning of the test sessions, each rat was placed in the middle of the open field. Number of rearings, locomotor activity (s), distance travelled (m), and time spent in the center of the open field (s) were recorded.

\section{Histological Preparation and Tissue Staining}

After completion of behavioral tests, rats were deeply anesthetized with an overdose of chloral hydrate and transcardially perfused with PBS followed by $4 \%$ paraformaldehyde. Brains were removed and cryoprotected in phosphate-buffered $30 \%$ sucrose solution for 2 days before they were cut on a cryostat $(40 \mu \mathrm{m})$. The sections were mounted on gelatine-coated slides and Thionin (Nissl) stained.

\section{Histological Investigation}

The extent of the mPFC lesions was determined in adult animals using a Zeiss (Göttingen, Germany) light microscope. Subjects with unilateral or misplaced lesions were deleted from further analysis. The absence of lesions was verified in sham-lesioned rats. The volume of the mPFC, including the subregions anterior cingulate, prelimbic, and infralimbic cortex, was determined using the MetaMorph image analysis system (Visitron-Systems, Purchheim, Germany) in all lesioned rats. The mPFC volume was measured in six consecutive sections (distance: $240 \mu \mathrm{m}$, since every sixth section was Nissl stained) starting at $3.2 \mathrm{~mm}$ anterior to bregma on the basis of the area on coronal sections and the distance between adjacent sections: $\left(\frac{1}{2}\right.$ area section $1+$ area $2+$ area $3+\ldots \frac{1}{2}$ area $\left.n\right) \times$ distance.

\section{Statistical Analysis}

The data for juvenile animals after mPFC lesion were analyzed using one-way analysis of variance (ANOVA), followed by post hoc Tukey's $t$-tests for pairwise comparisons. The effects of neonatal lesion and chronic pubertal cannabinoid treatment on play behavior, social behavior, and locomotor activity in adult rats were evaluated using two-way ANOVA, followed by post hoc Tukey's $t$-tests for pairwise comparisons. CPP was analyzed using a three-way ANOVA for repeated measure, followed by Tukey's $t$-tests for pairwise comparisons. An alpha value of 5\% was considered to represent a significant effect.

\section{RESULTS}

\section{Histology}

Neonatal mPFC lesions on pd 7 were visible in adult animals as tissue scars, tissue thinning, and cytoarchitectural abnormalities, which were restricted to the infralimbic, prelimbic, and anterior cingulate cortices (Figure 1). No subjects had to be removed from this study, since all lesions were restricted to medial prefrontocortical regions. The volume of the mPFC was significantly reduced in all neonatally lesioned rats, independent from the chronic cannabinoid administration during puberty compared to shams and controls (ANOVA: $\mathrm{F}_{2,40}=38.42 ; p<0.05$ ) (Table 1).

\section{Behavioral Testing}

\section{Play fighting, social behavior unrelated to play, and} self-grooming.

Play behavior in juvenile rats: Neonatally lesioned rats were significantly less involved in pinning behavior than controls (ANOVA: $\mathrm{F}_{2,35}=3.40 ; p<0.05$ ) (Figure 2). Both attacks initiated (ANOVA: $\mathrm{F}_{2,35}=1.79 ; p>0.05$ ) and attacks received (ANOVA: $F_{2,35}=0.89 ; p>0.05$ ) did not differ significantly between lesioned rats (IBO), shams, and controls. Supine defense, by initiating a complete rotation, was the most frequent form of facing defense in controls and shams. In contrast, lesioned rats were less likely to show this kind of defense (ANOVA: $\mathrm{F}_{2,35}=5.81 ; p<0.05$ ). Instead, neonatally mPFC-lesioned animals more frequently performed only a partial rotation (ANOVA: $F_{2,35}=6.53$; $p<0.05)$. No differences between the different treatment groups were detected with respect to evade (ANOVA: $\mathrm{F}_{2,35}=0.75 ; p>0.05$ ) or other defense strategies (ANOVA: $\left.\mathrm{F}_{2,35}=3.09 ; p>0.05\right)$.

These findings were confirmed by an evaluation of the percentage (of total defensive behaviors) of the different defensive strategies (data not shown). Here, lesioned rats also showed a reduced percentage of complete rotation (ANOVA: $\mathrm{F}_{2,35}=12.02 ; p<0.05$ ) and an increase in partial rotation (ANOVA: $F_{2,35}=25.56 ; p<0.05$ ) compared to shams and controls. The percentage of evade (ANOVA: $\mathrm{F}_{2,35}=0.98 ; p>0.05$ ) and other strategies (ANOVA: $\left.\mathrm{F}_{2,35}=2.74 ; p>0.05\right)$ was unaffected. Furthermore, neonatal 
$\mathrm{mPFC}$ lesions also induced a reduction in the percentage of pins, initiated by an own complete rotation (ANOVA: $\mathrm{F}_{2,35}=3.68 ; p<0.05$ ) (Table 2). No differences were observed in the probability of all three different treatment groups of defending against playful attacks (ANOVA: $\left.\mathrm{F}_{2,35}=0.77 ; p<0.05\right)$ (Table 2).

Play behavior in adult rats: Neither neonatal $\mathrm{mPFC}$ lesions nor pubertal chronic WIN treatment affected the

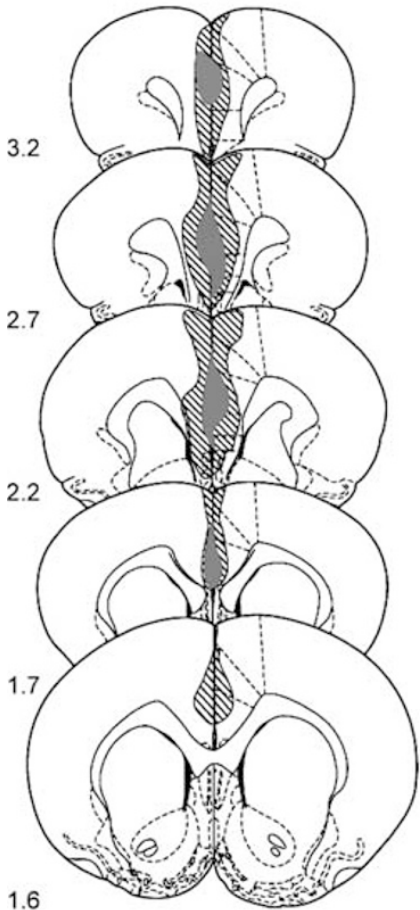

b

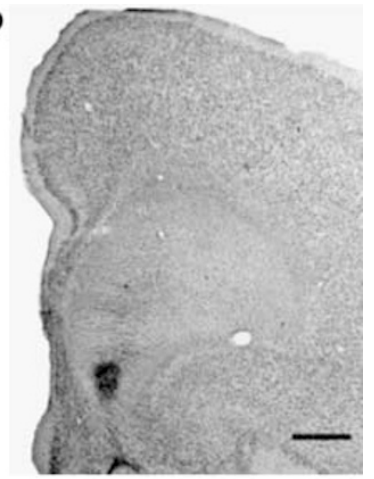

C

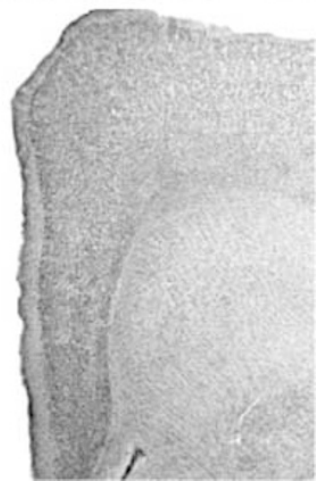

Figure I Schematical drawings depicting the lesion boundaries of neonatal mPFC excitotoxic lesions (a). Gray areas indicate the smallest and hatched areas indicate the largest extent of the lesion. The coordinates refer to distance in $\mathrm{mm}$ anterior of bregma. The photomicrographs of frontal sections show the effects of neonatal mPFC lesions in adult animals (b). The same region is also shown in a sham-lesioned animal of the same age (c). Neonatal ibotenate infusion into the mPFC induced tissue thinning as well as cytoarchitectural abnormalities in adult animals. Calibration bar: $200 \mu \mathrm{m}$. number of pins (ANOVA: surgery, $\mathrm{F}_{2,48}=1.62 ; p>0.05$; treatment, $\left.\mathrm{F}_{2,48}=0.27 ; p>0.05\right)$ or the number of attacks received from play partners (ANOVA: surgery, $\mathrm{F}_{2,48}=0.59$; $p>0.05$; treatment, $F_{2,48}=1.62 p>0.05$ ) (Figure 3 ). However, neonatally lesioned animals initiated significantly fewer attacks than shams and controls (ANOVA: $\left.\mathrm{F}_{2,48}=6.57 ; p<0.05\right)$, whereas chronic WIN treatment had

Table I Volume $\left(\mathrm{mm}^{3}\right)$ of the Entire mPFC (Left and Right Hemisphere) (+SEM) in Adult Rats

\begin{tabular}{lr}
\hline IBONWIN & $6.2( \pm 0.4)$ \\
IBO & $7.1( \pm 0.4)$ \\
SHAM/WIN & $10.0( \pm 0.3)$ \\
SHAM & $10.3( \pm 0.4)$ \\
CONTROLWIN & $11.0( \pm 0.5)$ \\
CONTROL & $9.9( \pm 0.4)$ \\
\hline
\end{tabular}

Neonatal ibotenate-induced lesions of the mPFC (IBO) induced a significant reduction of the $\mathrm{mPFC}$ volume in adulthood compared to sham $(p<0.00 \mathrm{I})$ and control groups $(p<0.00 I)(I B O, n=12$; IBO/WIN, $n=13$; SHAM, SHAM/WIN, CONTROL, and CONTROLNIN, $n=6$ ).

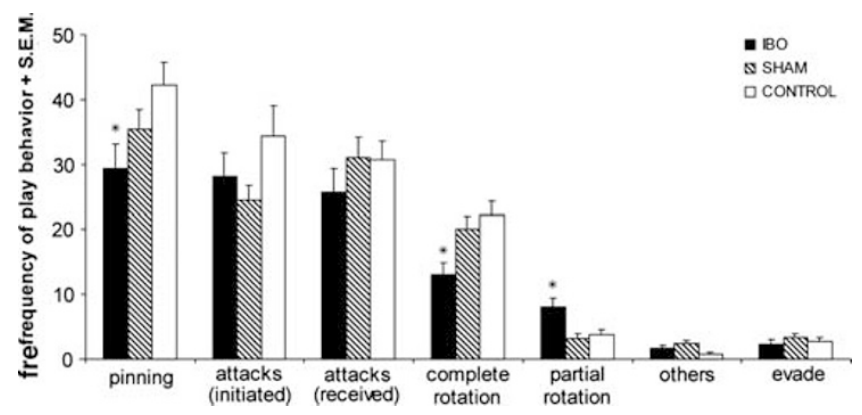

Figure 2 Frequency of different social play and defense behaviors in juvenile rats. Neonatally lesioned rats showed a reduced pinning frequency compared to controls $(* p=0.035)$. They also differed significantly from shams $(* p=0.040)$ and controls $(* p=0.008)$ in the use of complete rotation to the supine position. Furthermore, lesioned rats more frequently showed the partial rotation compared to shams $(* p=0.006)$ and controls $(* p=0.018)$ (IBO and SHAM, $n=13 ; \mathrm{CONTROL}, n=12)$. Neonatal lesions did not alter the propensity of juvenile rats for initiating attacks and being attacked by a play partner, and the frequency of evade and other defensive strategies.

Table 2 Percentage Analysis of Defensive Behavior in Juvenile and Adult Rats

\begin{tabular}{|c|c|c|c|c|c|c|}
\hline Juvenile (\%) \pm SEM & \multicolumn{2}{|c|}{ IBO } & \multicolumn{2}{|c|}{ SHAM } & \multicolumn{2}{|c|}{ CONTROL } \\
\hline Probability of defense in case of attack & \multicolumn{2}{|c|}{$96.9( \pm 0.8)$} & \multicolumn{2}{|c|}{$94.4( \pm 2.1)$} & \multicolumn{2}{|c|}{$96.1( \pm 0.9)$} \\
\hline Pins initiated by an own complete rotation & \multicolumn{2}{|c|}{$44.6( \pm 3.6)^{*}$} & \multicolumn{2}{|c|}{$56.8( \pm 3.4)$} & \multicolumn{2}{|c|}{$53.5( \pm 2.8)$} \\
\hline Adult (\%) \pm SEM & WIN & VEHICLE & WIN & VEHICLE & WIN & VEHICLE \\
\hline Probability of defense in case of attack & $98.7( \pm 1.7)$ & $92.6( \pm 2.2)$ & $91.5( \pm 2.1)$ & $96.3( \pm 2.1)$ & $99.5( \pm 0.5)$ & $95.1( \pm 2.8)$ \\
\hline
\end{tabular}

Neonatal mPFC lesions did not affect the probability of defense in juvenile rats when being attacked. However, lesioned rats were less likely than shams ( $P=0.033$ ) to initiate pinning (IBO and SHAM, $n=13$; CONTROL, $n=12$ ). Percentage analysis of defensive strategies in adults showed no differences between the different treatment groups in the probability of responding upon an attack and the percentage of initiated pinning (IBO, IBOMIN, SHAM, SHAM/WIN, CONTROL, and CONTROL WIN, $n=9$ ). 
no effect on the initiation of attacks (ANOVA: $\mathrm{F}_{2,48}=0.32$; $p>0.05)$. There were no differences between IBOs, shams, and controls for complete rotation (ANOVA: surgery, $\mathrm{F}_{2,48}=0.87 ; p>0.05$; treatment, $\left.\mathrm{F}_{2,48}=0.93 ; p>0.05\right)$, partial rotation (ANOVA: surgery, $\mathrm{F}_{2,48}=1.23$; $p>0.05$; treatment, $\left.\mathrm{F}_{2,48}=1.44 ; p>0.05\right)$, and the use of other defense strategies (ANOVA: surgery, $\mathrm{F}_{2,48}=0.02 ; p>0.05$; treatment, $\mathrm{F}_{2,48}=0.07 p>0.05$ ) (Figure 4). Lesioned rats that had received the chronic cannabinoid treatment more often showed the defensive behavior evade than all other groups (ANOVA: interaction effect, $\mathrm{F}_{2,48}=3.54 ; p<0.05$ ).

These effects were confirmed by the percentage evaluation of defensive behaviors shown in response to the number of attacks received (data not shown). No differences between groups were detected for complete rotation (ANOVA: surgery, $\mathrm{F}_{2,48}=0.86 ; \quad p>0.05$; treatment, $\mathrm{F}_{1,48}=0.54 p>0.05$ ), partial rotation (ANOVA: surgery, $\mathrm{F}_{2,48}=1.98 ; p>0.05 ;$ treatment, $\left.\mathrm{F}_{, 48}=0.04 p>0.05\right)$, and other defensive strategies (ANOVA: surgery, $F_{2,48}=0.11$; $p>0.05$; treatment, $\left.\mathrm{F}_{1,48}=0.01 p>0.05\right)$. The probability of lesioned animals that had received the chronic cannabinoid

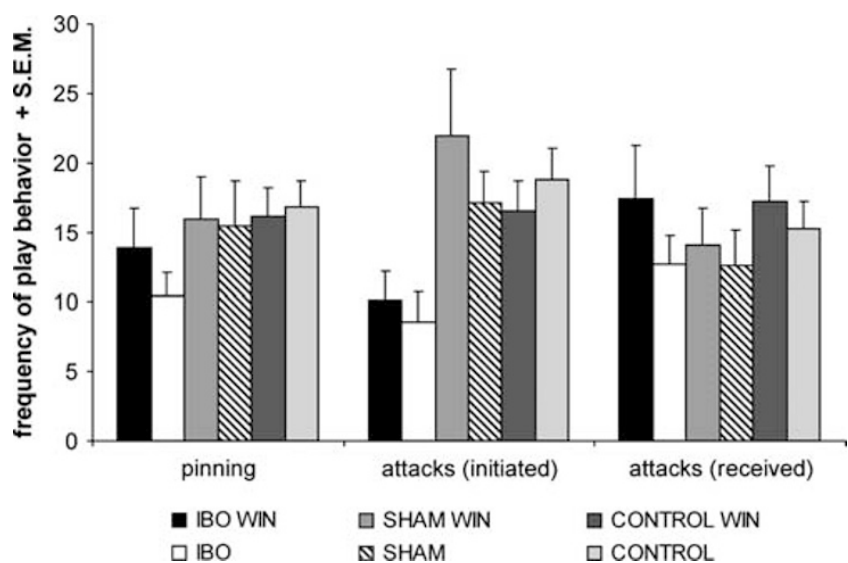

Figure 3 Frequency of social play behavior in adult rats. No effect was seen between the different treatment groups in the frequency of pinning and attacks received from play partners. However, all lesioned rats were less likely to initiate attacks than shams $(p=0.004)$ and controls $(p=0.020)$ (IBO, IBOMIN, SHAM, SHAM/WIN, CONTROL and CONTROLMIN, $n=9)$.

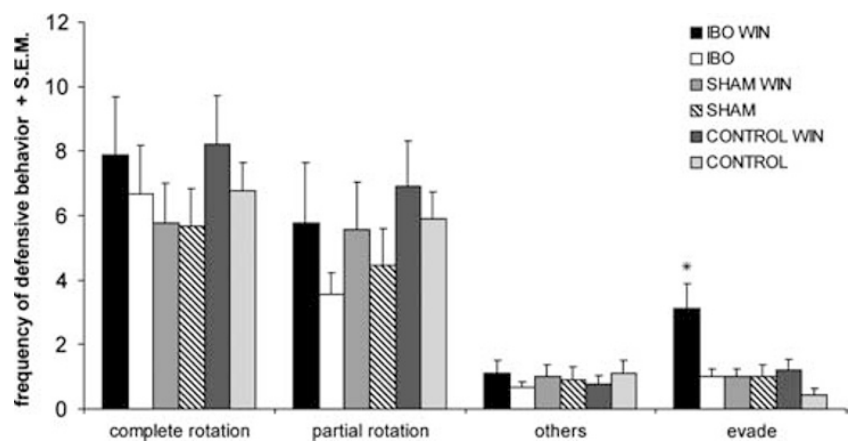

Figure 4 Frequency of defensive behavior in adult rats. No effects were seen in the use of complete rotation, partial rotation, and other defensive strategies between treatment groups. However, lesioned, WIN-treated rats showed a significant increase in the use of evade as defense strategy compared to vehicle-treated groups $(* p<0.00 \mathrm{I})(\mathrm{IBO}, \mathrm{IBO} / \mathrm{WIN}, \mathrm{SHAM}$, SHAM/WIN, CONTROL and CONTROL/WIN, $n=9)$. treatment to adopt evade as defense response upon an attack was significantly increased compared to all other groups (ANOVA: interaction effect, $\mathrm{F}_{2,48}=3.21 ; p<0.05$ ). There were no differences between the different adult groups for the percentage of pins, initiated by an own complete rotation (ANOVA: surgery, $\mathrm{F}_{2,48}=2.04 ; p>0.05$; treatment, $\mathrm{F}_{1,48}<0.01 ; p>0.05$ ) (Table 2). Similar to juvenile rats, no differences were observed in the probability of all adult treatment groups of defense against playful attacks (ANOVA: surgery, $\mathrm{F}_{2,48}=1.81 ; p>0.05$; treatment, $\mathrm{F}_{1,48}<0.01 ; p>0.05$ ) (Table 2).

Percentage of play during light phase recording: The number of play behaviors (pinning, attacks initiated and received) that occurred during light phase were scored and evaluated as the percentage of the total number of play that appeared during light and dark (Figure 5). No percentage evaluation of defensive behavior was carried out for the light phase, because only few playful activities occurred during this phase. No effects were seen in juvenile animals (Figure 5a), where barely any play occurred at all during the light phase (ANOVAs: pinning, $\mathrm{F}_{2,35}=0.14 ; p>0.05$; attacks (initiated), $\quad \mathrm{F}_{2,35}=0.77 ; \quad p>0.05 ; \quad$ attacks (received), $\left.\mathrm{F}_{2,35}=0.01 ; p>0.05\right)$. However, retesting of adult animals revealed a WIN effect for all groups (Figure 5b). Those animals that had received the chronic cannabinoid administration during puberty showed a significant increase in the occurrence of pinning (ANOVA: $\mathrm{F}_{1,48}=22.9 ; p<0.05$ ), attacks initiated (ANOVA: $\mathrm{F}_{1,48}=16.3 ; p<0.05$ ), and attacks received (ANOVA: $\mathrm{F}_{1,48}=19.4 ; p<0.05$ ) during the light
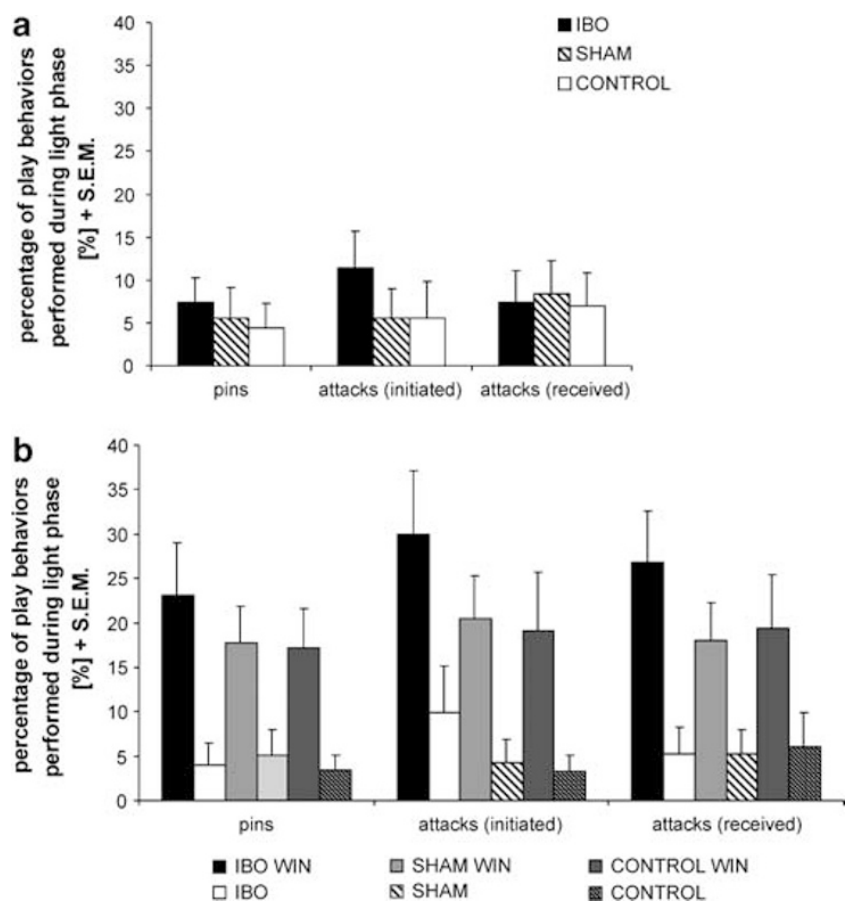

Figure 5 Percentage of the occurrence of social play during light phase in juvenile (a) and adult rats (b). No differences could be detected between the different treatment groups in juvenile rats (IBO and SHAM, $n=13$; CONTROL, $n=12$ ). Chronic pubertal WIN treatment significantly increased the occurrence of play fighting in adult rats while lights were on $(p<0.00 I)(I B O, I B O M I N, S H A M, S H A M / W I N, C O N T R O L$ and CONTROL/WIN, $n=9$ ). 
phase compared to vehicle-treated rats. No effects of neonatal mPFC lesions were found (ANOVAs: pinning, $\mathrm{F}_{2,48}=0.42 ; \quad p>0.05 ; \quad$ attacks (initiated), $\quad \mathrm{F}_{2,48}=1.63$; $p>0.05$; attacks (received), $\mathrm{F}_{2,48}=0.53 ; p>0.05$ ).

Social behavior in juvenile rats: Neonatally lesioned and sham-lesioned rats showed a significant reduction in the total amount of social behaviors compared to controls (Figure 6) (ANOVA: $\mathrm{F}_{2,35}=10.88 ; p<0.05$ ). This effect apparently arised from a significantly reduced grooming behavior (ANOVA: $F_{2,35}=14.74 ; p<0.05$ ) and a reduction in crawl over (ANOVA: $F_{2,35}=4.09 ; p<0.05$ ) of shams and lesioned rats. There were no significant differences between the different treatment groups regarding social exploration (ANOVA: $\mathrm{F}_{2,35}=1.19 ; p>0.05$ ), but lesioned rats showed a significant increase in tail manipulation compared to shams and controls (ANOVA: $\mathrm{F}_{2,35}=4.24 ; p<0.05$ ).

Social behavior in adult rats: In adult animals (Figure 7), no surgery or treatment effects were seen on tail manipulation (ANOVA: surgery, $\mathrm{F}_{2,48}<0.01 ; p>0.05$; treatment, $\left.\mathrm{F}_{1,48}<0.01 ; p>0.05\right)$ and on the total amount of social behavior (ANOVA: surgery, $\mathrm{F}_{2,48}=1.55 ; p>0.05$; treatment, $\left.\mathrm{F}_{1,48}=0.15 ; p>0.05\right)$. Neonatal lesions had no effects on the frequency of crawl over (ANOVA: $F_{2,48}=1.97 ; p>0.05$ ), but WIN-treated animals showed a significant reduction of this social behavior (ANOVA: $F_{1,48}=4.16 ; p<0.05$ ). Social grooming was significantly reduced in lesioned rats (ANOVA: $\mathrm{F}_{2,48}=7.96 ; p<0.05$ ) and WIN treatment also induced a reduction in grooming behavior (ANOVA: $\left.\mathrm{F}_{2,48}=12.52 ; p<0.05\right)$. A significant interaction effect between surgery and pubertal cannabinoid treatment for social exploration was found (ANOVA: $F_{2,48}=3.23$; $p<0.05)$. Only WIN-treated sham-lesioned and lesioned rats showed a significant enhancement of social exploration.

Self-grooming behavior: When tested as juveniles, lesioned and sham-lesioned rats showed a significant reduction in self-grooming behavior compared to controls

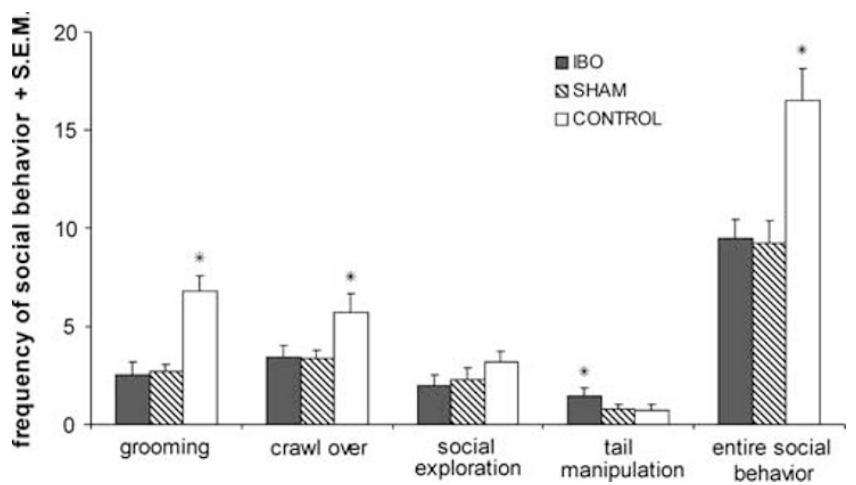

Figure 6 Frequency of social behavior in juvenile rats. Neonatally lesioned and sham-lesioned rats showed a significant reduction in social grooming (IBO: * $p<0.00 \mathrm{I}$; SHAM: * $p<0.00 \mathrm{I}$ ), crawl over (IBO: * $p=0.04 \mathrm{I}$; SHAM: $* p=0.049)$, and the total amount of social behaviors (IBO: $* p=0.00$ I; SHAM: $* p<0.00 \mathrm{I})$ compared to controls. There were no significant differences between the different treatment groups in social exploration, but lesioned rats showed a significant increase in tail manipulation compared to shams $(* p=0.044)$ and controls $(* p=0.043)$ (IBO and SHAM, $n=13$; CONTROL, $n=12$ ).
(ANOVA: $\mathrm{F}_{2,35}=5.76 ; p<0.05$ ) (values: $\mathrm{IBO}=8.0 \pm 0.8$; $\mathrm{SHAM}=8.1 \pm 1.0 ;$ and $\mathrm{CONTROL}=12.2 \pm 1.2$ ). In adult animals, reduced self-grooming was only observed in neonatally lesioned rats (ANOVA: $\mathrm{F}_{2,48}=6.42 ; p<0.05$ ) (values: $\quad \mathrm{IBO} / \mathrm{WIN}=6.8 \pm 0.9 ; \quad \mathrm{IBO}=6.2 \pm 1.0 ; \quad \mathrm{SHAM} /$ $\mathrm{WIN}=9.2 \pm 1.3 ; \quad \mathrm{SHAM}=10.2 \pm 1.5 ; \quad$ CONTROL/WIN $=$ $9.8 \pm 0.9$; and CONTROL $=11.6 \pm 1.3$ ). No effect of the chronic cannabinoid treatment was found (ANOVA: $\left.\mathrm{F}_{1,48}=1.19 ; p>0.05\right)$.

CPP for social contact. CPP for social contact was reduced in lesioned and sham-lesioned animals that had received chronic cannabinoid administration during puberty (Figure 8). A direct comparison of the time spent in each compartment for the different treatment groups (surgery and cannabinoid treatment) revealed an interaction effect (ANOVA: $\mathrm{F}_{2,64}=3.53 ; p<0.05$ ). All groups developed a

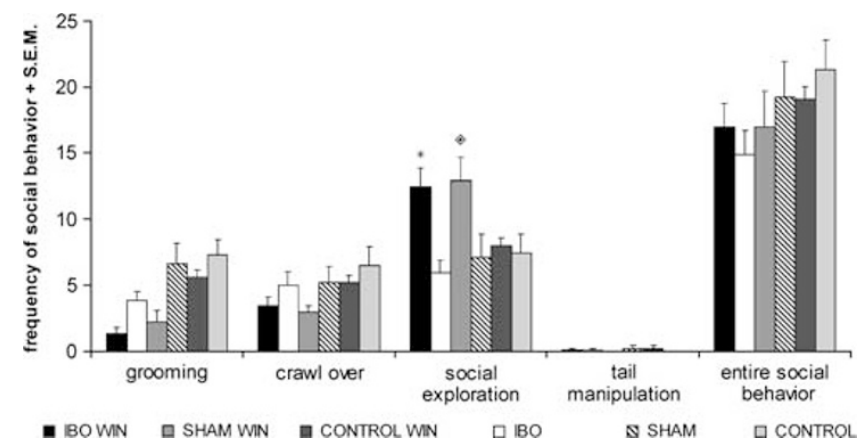

Figure 7 Frequency of social behavior in adult rats. In adult animals, no effects were seen in tail manipulation and the total amount of social behavior. Neonatal lesions had no effects on the frequency of crawl over, but all cannabinoid-treated animals showed a significant reduction of crawl over $(p=0.047)$. Social grooming was significantly reduced in all lesioned rats $(p<0.00 \mathrm{I})$ compared to controls and cannabinoid treatment also induced a general reduction in grooming behavior $(p=0.00 \mathrm{I})$. Furthermore, social exploration was significantly enhanced in WIN-treated shamlesioned $(p=0.005)$ and lesioned $(* p<0.00 \mathrm{I})$ rats compared to vehicletreated groups (IBO, IBO/WIN, SHAM, SHAM/WIN, CONTROL and CONTROL $/ \mathrm{WIN}, n=9)$.

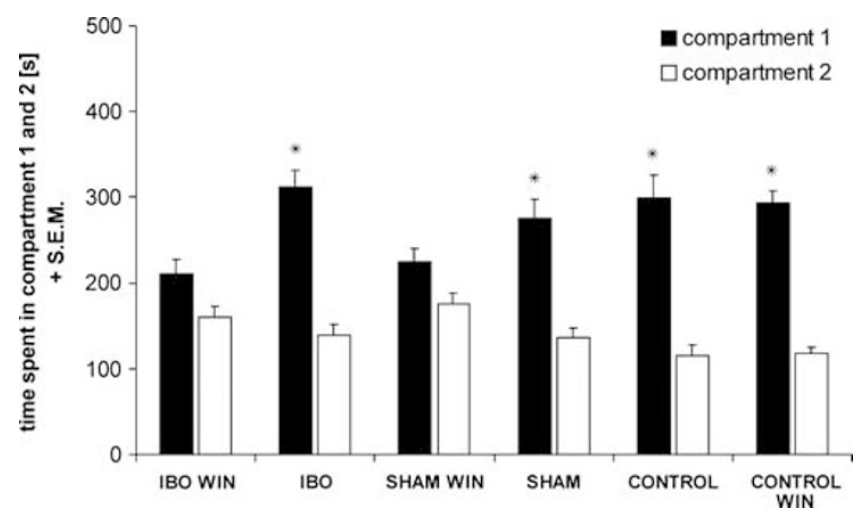

Figure 8 Time spent in compartment | (social partner) and compartment 2 during the CPP test for social contact. All groups developed a significant place preference for the compartment associated with social contact (IBO: *p $<0.00$ I; SHAM: *p<0.00 I; CONTROLMIN: * $p<0.00$ I; CONTROL: $* p<0.00 I)(\mathrm{IBO} / \mathrm{WIN}, \mathrm{IBO}, \mathrm{SHAM} / \mathrm{NIN}$, and CONTROL WIN, $n=12$; SHAM and CONTROL, $n=11$ ), except WIN-treated lesioned and sham-lesioned rats that did not develop a place preference at all. 
significant place preference for compartment 1 (social partner), except for the WIN-treated lesioned and shamlesioned rats. A preconditioning place preference test showed that the animals did not show an initial preference for either of the conditioning compartments upon the first exposure (data not shown) (ANOVA: $\mathrm{F}_{2,64}=0.12 ; p>0.05$ ).

\section{Open field.}

Juvenile: No effects of mPFC lesions in peripubertal rats on open field behavior were found (Table 3). Neither locomotor activity $\left(\mathrm{F}_{2,67}=0.19 ; \quad p>0.05\right)$, rearings $\left(\mathrm{F}_{2,67}=0.32 ; p>0.05\right)$, distance travelled $\left(\mathrm{F}_{2,67}=0.30\right.$; $p>0.05)$, nor the time spent in the center of the open field $\left(\mathrm{F}_{2,67}=0.67 ; p>0.05\right)$ was affected.

Adult: No effects on open field behavior of mPFC lesions and WIN treatment were found in adult rats (Table 3) with respect to locomotor activity (ANOVA: surgery, $\mathrm{F}_{2,65}=1.38 ; p>0.05$; treatment, $\left.\mathrm{F}_{1,65}=0.46 ; p>0.05\right)$, rearings (ANOVA: surgery, $\mathrm{F}_{2,65}=0.61 ; p>0.05$; treatment, $\mathrm{F}_{1,65}=0.48 ; p>0.05$ ), and distance travelled (ANOVA: surgery, $\quad \mathrm{F}_{2,65}=1.00 ; \quad p>0.05 ; \quad$ treatment, $\mathrm{F}_{1,65}=1.84$; $p>0.05)$. Time spent in the center of the open field was significantly reduced in all WIN-treated groups compared to vehicle-treated animals (ANOVA: $\mathrm{F}_{1,65}=6.94 ; p<0.05$ ). No effects were seen of neonatal $\mathrm{mPFC}$ lesions (ANOVA: $\left.\mathrm{F}_{2,65}=0.64 ; p>0.05\right)$.

\section{DISCUSSION}

The present data show that neonatal excitotoxic lesions of the mPFC in combination with chronic pubertal treatment with the cannabinoid agonist WIN lead to disturbances of play fighting, social behavior, and self-grooming in juvenile and adult rats. In addition to specific lesion effects, surgery by itself induced a vulnerability for the pubertal cannabinoid treatment in lesioned and sham-lesioned rats with respect to nonplayful social behavior.

\section{Play Fighting}

Neonatal lesions reduced pinning in juvenile rats compared to shams and controls. This effect does not seem to be due to a loss of play motivation since no reduction was detected in the number of initiated or received attacks, and also the probability of defending against playful attacks was not affected. Similarly, reduced pinning cannot be accounted for by locomotor deficits since all groups performed the full range of defensive responses available for deflecting attacks to the nape and did not differ in their locomotor activity in the open field. In the juvenile rat, the most frequent type of facing defense is to rotate completely to a supine position, thus blocking access to the nape and creating the opportunity to use the limbs to ward off the attacker (Pellis and Pellis, 1997). Neonatal mPFC-lesioned rats were less likely to adopt this juvenile pattern of defense compared to controls and shams, but showed an increase in the total number of partial rotations. Partial rotation, an adult-like pattern of defense, involves an incomplete rotation around the longitudinal axis, while standing on the hindlegs. From this position, the defender can either rear to an upright position or push against the attacker with the hip (Pellis et al, 1992; Pellis and Pellis, 1997). Furthermore, we found a significant reduction in lesioned animals in the probability of initiating a pinning configuration by adopting a complete rotation. This means that lesioned rats did not only show a lower incidence of pinning but were also less likely to initiate a pin themselves by adopting the bottom position. Therefore, neonatal excitotoxic lesions of the mPFC lead to a behavioral shift of social play in juvenile rats to an adultlike pattern of defense. This behavioral shift induces a reduction in pinning and shortens the interactions between the play partners. Notably, an almost identical disturbance of play behavior was described before by Pellis et al after neonatal decortication in rats. The authors suggested that the cortex is important for the selection of appropriate defensive behaviors. It was proposed that the cortex inhibits the more adult-like response that would tend to shorten the length and repetitiveness of juvenile play (Pellis et al, 1992).

Table 3 Mean Locomotor Activity (s), Number of Rearings, and Distance Travelled (m) for Juvenile (pd 30) (IBO, $n=24 ; \mathrm{SHAM}$ and CONTROLS, $n=22)$ and Adult Rats (pd 80) (IBO, SHAM/WIN and CONTROLNIN $n=12 ; \mathrm{SHAM}, n=1 \mid$; CONTROL, $n=10$, IBO/WIN, $n=13$ )

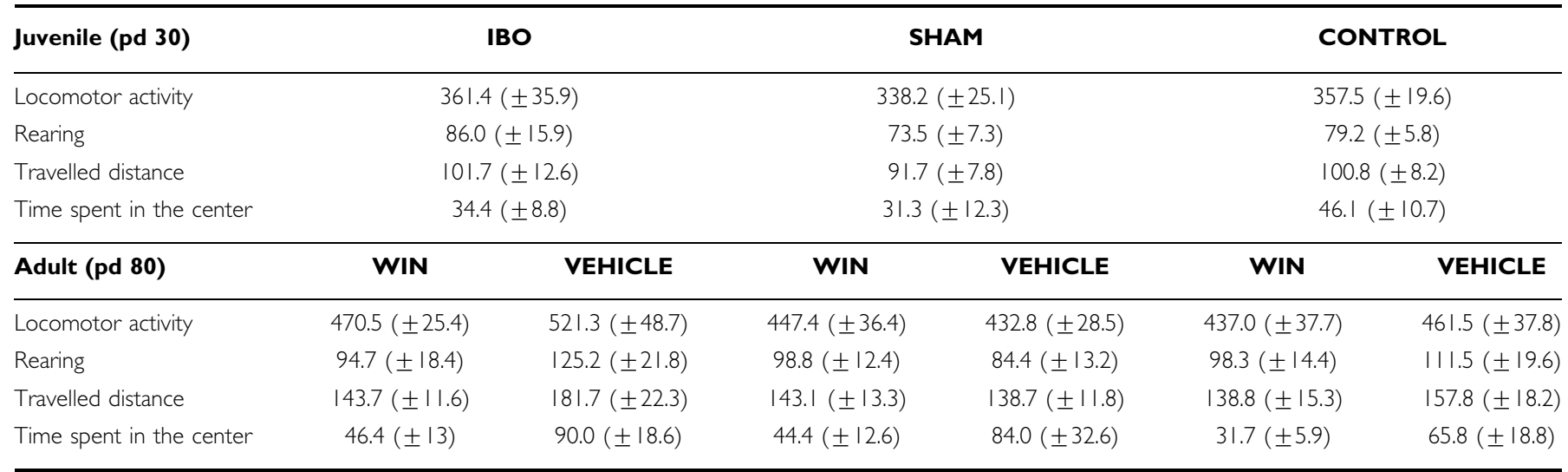

No effects were seen in locomotor activity, rearing, and distance travelled neither in juvenile nor in adult rats after mPFC lesion and WIN treatment. However, all WIN-treated groups spent significantly less time in the center of the open field $(* p=0.0 \mathrm{II})$. 
The findings of the present study lend support for a role of the mPFC in inhibitory control over the adult-like behavioral defense in juvenile rats. This is consistent with the general functions of the PFC: the temporal organization of behavior and cognitive behavioral control (Fuster, 2002). Cognitive control processes enable response flexibility by selecting contextually relevant perceptual, mnemonic, and motor representations or processing pathways, and organizing and integrating these representations (Badre and Wagner, 2004).

Beside a cortical involvement in behavioral selection during juvenile play, it was also shown that dopamine depletion by neonatal 6-OHDA lesions of the nucleus accumbens (NAC) and caudate putamen disrupted the organization of play behavior in juvenile rats. Patterns of social play were displayed in a normal way, but lesioned animals responded inappropriately to play initiation and were easily distracted (Pellis et al, 1993). Input to these striatal structures comes inter alia from the amygdala (Kelley et al, 1982), lesions of which have also been shown to disrupt pinning in juvenile male rats (Wolterink et al, 2001; Daenen et al, 2002). Furthermore, lesions of the dorsomedial and parafascicular thalamus also decrease social play (Vanderschuren et al, 1997). Therefore, a deficient connection between the mPFC and important cortical projection areas, including the amygdala, the thalamus, and the NAC, induced by the neonatal cortical lesion, might contribute to the changes of juvenile defensive behavior observed in the present study. Furthermore, the mPFC itself exerts an important regulatory control on the subcortical mesolimbic dopamine system by efferent projections to the ventral tegmental area, which controls the dopamine output in the NAC (Carr and Sesack, 2000). It has been shown before that neonatal $\mathrm{mPFC}$ lesions induce a disturbance in the functional development and maturation of the mesolimbic dopaminergic system (Flores et al, 1996; Brake et al, 2000; Bennay et al, 2004). Hence, the disruption of juvenile play behavior by neonatal mPFC lesions might be due to a sequela of developmental pathologies including disruption of normal functioning of mesostriatal dopamine systems.

Inadequate social behavior is a notable characteristic of early brain damage (Eslinger et al, 2004) and several developmental psychiatric disorders, including schizophrenia and autism (DSM IV, American Psychiatric Association, 1994). A recent functional MRI study showed a deficit in the left prefrontal cortex in schizophrenia during a socioemotional task. The integrity of the PFC seems thus to be crucial for adequate response selection in a social context (Russell et al, 2000).

In adult rats, no differences could be found between treatment groups in pinning frequency, the number of attacks received, and the probability of defending against playful attacks. However, in neonatally lesioned rats, the number of attacks to the nape of their play partners was reduced. Since the frequency of playful attacks is generally regarded as a measure for play motivation (Pellis et al, 1992), the reduction of attacks may be due to a loss in the motivation of lesioned rats to engage in play. Furthermore, lesioned rats that had received the chronic cannabinoid administration were more likely to evade upon an attack compared to all other treatment groups, which was shown both by the total and relative (percent) number of evades. The enhanced use of evade behavior upon an attack shortens playful interactions. As mentioned above, the neonatal $\mathrm{mPFC}$ lesion reduced the motivation for play in adult rats. The chronic cannabinoid administration in pubertal rats exacerbates this lack of interest in playful activities, since WIN-treated lesioned rats not only initiate less attacks but also evade more often upon attack than all other treatment groups. Lesioned cannabinoid-treated rats also showed reduced social CPP (also discussed below), suggesting reduced motivation for social interactions.

Interestingly, the changes in defense and the initiation of attacks seen in the present study in males after neonatal lesions and chronic WIN treatment resemble the female pattern of play. The frequency of attacks is lower in playing females than in males, and female rats are more likely than males to evade as an defensive maneuver (Pellis et al, 1997). It has been suggested that this female defensive response in play might arise inter alia from enhanced anxiety (Pellis et al, 1997). Previous studies have shown that cannabinoids increase neophobic responses and anxiety in rats (Arevalo et al, 2001) and in humans (Hall and Solowij, 1998). In our study, WIN treatment induced center avoidance in the open field suggesting increased anxiety (Cannizzaro et al, 2001; Jinks and McGregor, 1997). It is well known that cannabinoid receptor agonists enhance the release of endogenous opioids, and it was suggested by Marin et al (2003) that the anxiogenic-like effect of cannabinoids could be mediated by an interaction with the $\kappa$-opioid receptor. The $\mathrm{mPFC}$ is also involved in the expression of anxiety, mainly through its modulatory impact on the amygdala (Milad and Quirk, 2002; Grace and Rosenkranz, 2002; Rosenkranz and Grace, 2001; Rangel et al, 2003). Therefore, the reduced motivation to play in adult rats, after neonatal lesions and chronic pubertal cannabinoid administration, might be due to enhanced anxiety.

We also evaluated the percentage of play behavior that appeared during the light period relative to the total occurrence of play. No differences were detected after neonatal lesions in juvenile play during the light phase, where play behavior was seldom. However, in adult rats, chronic pubertal cannabinoid treatment increased play behavior during the light phase. This effect is probably not due to a general increase in motor activity since WINtreated rats did not show an increase in overall play behavior, and activity in the open field. Likewise, this effect can not be due to a general reduction in anxiety, since WINtreated groups showed a higher open field center avoidance than vehicle-treated rats, which is considered an index of anxiety (Cannizzaro et al, 2001; Jinks and McGregor, 1997). We assume that the unusual occurrence of play during the light phase after pubertal WIN treatment may be due to changes in the sleep-waking cycle, where the cannabinoid system plays a regulatory role (Adams and Barratt, 1975; Murillo-Rodriguez et al, 1998; Santucci et al, 1996).

\section{Social Behavior and CPP for Social Contact}

Social behavior unrelated to play and CPP for social contact were used to assess the effects of neonatal lesions and peripubertal WIN treatment on the development of social behavior. As juveniles, neonatally lesioned and sham- 
lesioned rats showed reduced grooming and crawl over and thus a decrease in the total amount of social behaviors compared to controls. Additionally, a significant increase in tail manipulation was detected in lesioned rats compared to shams and controls. Tail manipulation occurs most frequently at the ages of 17-20 days in rats and normally remains at a low incidence as the animals grow older (Pellis and Pellis, 1997). Therefore, increased tail manipulation in lesioned rats suggests inadequate behavioral selection, similar to the disturbances in the selection of defensive play strategies described before.

Although it is known that the PFC is involved in social behavior (De Bruin, 1990; Wood, 2003), the adverse lesion effects on social grooming and crawl over seen in our study are probably not caused by cortical lesions per se, because shams were impaired as well. These findings support other studies showing that cryoanesthesia (Nunez et al, 1998; Nunez et al, 2000; Kolb and Cioe, 2001) and maternal separation (Matthews and Robbins, 2003; Newport et al, 2002) in neonatal rats affect both brain and behavior and underscore the importance of the use of naïve control groups in neonatal lesion studies. Although maternal separation in our study occurred only once and did not exceed $1 \mathrm{~h}$, this does not exclude the possibility of subsequent disturbances in social development. It has been shown that neonatal isolation has immediate effects on various stress-responsive systems, since plasma corticosterone levels are significantly increased within $30 \mathrm{~min}$ of isolation (McCormick et al, 1998), and that stress and concomitant corticosterone secretion facilitates mesolimbic dopaminergic activity (McCormick et al, 2002; Pani et al, 2000). Given that stress clearly affects social behavior, and that early life experience affects an individual's stress response (Tang et al, 2003), it is possible that neonatal surgery impairs the development of social skills. These findings appear to be incongruent with the stress-hyporesponsive period in rodents ( $p d 4-14$ ), where the adrenal response to stress is minimal (Levine, 2001; Schmidt et al, 2002). However, there is evidence that the normal dam-pup interaction, particularly maternal tactile stimulation of the pup, actively inhibits the endocrine stress response in neonatal rats. Thus, during early development, most of the peripheral and central stress-responsive systems are capable of being activated (Levine, 2001).

In adult animals, the pubertal cannabinoid treatment reduced crawl over and social grooming behavior and the neonatal mPFC lesion also decreased social grooming. Additionally, an enhancement of social exploration in WINtreated shams and lesioned rats was found. Similar effects were seen in CPP for social contact, where only WIN-treated lesioned and sham-lesioned rats failed to develop a place preference. Studies on cannabinoid actions on nonaggressive social behavior are rare, but indicate that acute and chronic administration of $\Delta^{9}$-tetrahydrocannabinol reduces social interaction in rodents (Van Ree et al, 1984; Sieber et $a l, 1980)$ and induces social withdrawal and isolation in baboons (Sieber, 1982). Additionally, a recent study showed reduced social interaction in cannabinoid receptor (CB1) knockout mice (Haller et al, 2004). The mechanisms by which these cannabinoid-induced social impairments are mediated are unknown so far, but an interaction with stressresponsive systems might be involved. It has been shown that cannabinoids stimulate the hypothalamus-pituitaryadrenal (HPA) axis as reflected by elevations of corticosterone and adrenocorticotropin hormone plasma levels (Manzanares et al, 1999), and that chronic perinatal cannabinoid treatment increases corticosterone levels in adult rats (Navarro et al, 1994). Beside the important role of corticosterone in the regulation of dopaminergic neurotransmission (Czyrak et al, 2003; Pani et al, 2000), it was proposed that $\mathrm{D} 1$ receptors might oppositely regulate the release of corticosterone by activation of neurons in the paraventricular nucleus of the hypothalamus (Czyrak et al, 2003). There is evidence that pubertal cannabinoid treatment persistently alters mesolimbic dopaminergeric activity in adult rats (Schneider and Koch, 2003; Pistis et al, 2004). Therefore, social impairments induced by pubertal cannabinoid administration may derive from an altered dopaminergic modulation of the HPA axis. The findings of reduced social behavior by neonatal lesions and by pubertal WIN treatment are also consistent with the withdrawal from playful activities in lesioned, WIN-treated rats shown in the present study.

Similar behavioral effects of early cortical disturbances are seen in humans. Patients with early lesions of the PFC show long-term impairments in social behavior, failure to respond to behavioral interventions, and show defective social and moral reasoning (Anderson et al, 1999; Eslinger et al, 2004). These studies are consistent with our present findings and indicate a crucial role of the mPFC in social development of mammals. In addition, the lesion-induced disturbances of juvenile play behavior described in the present study may also contribute to the social deficits observed, since play fighting is of major importance for the development of communicative skills and appropriate behavioral patterns. It was shown before that play deprivation in juvenile rats causes abnormal patterns of social, sexual, and aggressive behaviors in adulthood. Therefore, social play might function to establish social organization, serve to develop the ability to express and understand intraspecific communicative signals, and to cope with social conflicts (Vanderschuren et al, 1997).

The WIN-induced enhancement of social exploration and reduction of the rewarding value of social interaction in isolated rats was only seen in sham-lesioned and lesioned rats, suggesting an interaction between neonatal surgery and pubertal cannabinoid treatment. The increase in anogenital and body investigation might be caused by disturbances in social recognition. Thereby, the normally rewarding value of contact to a familiar social partner during CPP might be perceived as aversive in WIN-treated shams and lesioned rats, since interactions with unfamiliar conspecifics induce social stress (Blanchard et al, 2001).

As mentioned before, autistic children show impoverished or atypical social behavior (Waterhouse et al, 1996; Grossman et al, 1997). Likewise, social withdrawal and social isolation are among the key components of negative symptoms in schizophrenia (Daenen et al, 2002; DSM IV, American Psychiatric Association, 1994). Furthermore, it has been shown that limited social functions in childhood are precursors of impaired social function in adulthood (Goldberg and Schmidt, 2001). Social withdrawal and isolation have been identified as schizophrenic prodromal behaviors in children (Moller and Husby, 2000). The 
complex social disturbances found in the present study in juvenile rats might provide a model to study the neuronal correlates of such early stages of psychiatric diseases.

\section{Self-Grooming}

Care of the skin and fur protects the animal from injury and infections from ectoparasites and other agents and plays a role in thermoregulation. Laboratory rats spend about $40 \%$ of their waking time engaged in self-grooming, which is a complex instinctive behavior that is little affected by individual experience (Robertson et al, 1999). In juvenile rats, self-grooming was reduced in all groups that underwent surgery compared to controls. However, in adult rats the deficient self-grooming behavior only persisted in neonatally lesioned rats. Disturbances in self-grooming in adult animals may relate to a maldevelopment of mesocorticolimbic systems induced by neonatal mPFC lesion. Although various neurotransmitters can influence selfgrooming behavior, dopamine is particularly important. Self-grooming is differently modulated by stimulation of D1 and D2 receptors (Serafim and Felicio, 2001) and is impaired by lesions of brain regions that are rich in dopaminergic inputs, for example, the striatum, the hippocampus, and the cortex (Cromwell and Berridge, 1996; Vanderwolf et al, 1978). In particular, the interaction between those different brain regions seems to play a crucial role in the regulation of self-grooming behavior (Vanderwolf et al, 1978). It has been shown that neonatal lesions of the mPFC alter the functional development of mesocortical networks (Brake et al, 2000; Bennay et al, 2004). Therefore, the disturbances in self-grooming behavior in adult rats after neonatal cortical lesions may be caused by persistent disturbances of dopaminergic systems.

The reduction of self-grooming behavior in juvenile rats cannot be explained by the lesion of the mPFC, since shamlesioned rats were affected as well. This effect might therefore relate to the general surgical stress that was discussed before. However, the sham effect disappeared during further pubertal development since sham-lesioned groups did not show an impairment in self-grooming behavior as adults.

\section{Conclusions}

In the present study, complex disturbances of social play, social behaviors unrelated to play, self-grooming, and reduced prefrontocortical volume in rats are shown following neonatal mPFC lesions on pd 7 and pubertal cannabinoid treatment.

Early prefrontal damage in humans leads to severe disturbances in social behavior in adulthood (Eslinger et al, 2004). However, not only early brain lesions but also subtle changes of brain development can have adverse effects on social behavior later in life. Capitalizing on the neurodevelopmental hypothesis of psychiatric disorders, several animal models were set up in the past decade, including neonatal excitotoxic lesions of the ventral hippocampus (Lipska et al, 1995, 2002a, b), the amygdala (Wolterink et al, 2001; Daenen et al, 2002), and also the mPFC (Flores et al, 1996; Brake et al, 2000; Bennay et al, 2004; Schwabe et al, 2004). The study of neural systems involved in disturbances of social functioning in psychiatric disorders has become increasingly popular in recent years, since impaired social skills are among the hallmarks of psychiatric diseases (DSM IV, American Psychiatric Association, 1994). However, animal models for negative symptoms of psychiatric disorders are quite rare (Ellenbroek and Cools, 2000).

Neonatal lesions of the ventral hippocampus induce disturbances of social interaction (Becker et al, 1999; Sams-Dodd et al, 1997) and social memory in rats (Becker and Grecksch, 2000). Neonatal amygdala lesions have been shown to disrupt juvenile social play, whereas neonatal hippocampal lesions do not (Daenen et al, 2002; Wolterink et al, 2001). However, those studies did only evaluate duration and frequency of pinning, which by itself is an insufficient measure for the mechanisms of an altered frequency of social play (Pellis et al, 1992) and did not use unoperated control groups. Therefore, further studies are needed to clarify these lesion effects on social play and social behavior.

Taken together, our data indicate that the mPFC is not necessary for juvenile rats to engage in social play per se, but is important for an adequate juvenile response selection. The present findings suggest that the mPFC contributes to the development of adult social behavioral skills, social motivation, and self-grooming. This crucial role of the mPFC in behavioral development may be mediated by facilitating juvenile social play, since normal play fighting is important for the development of communicative skills and appropriate behavioral patterns (Vanderschuren et al, 1997). Moreover, our findings suggest an involvement of the cannabinoid system in anxiety and social behavior. Additive effects of neonatal surgeryinduced stress or cortical lesions and pubertal cannabinoid administration are also shown.

The disturbances of social and nonsocial behavior shown in the present study in rats are comparable to some symptomatological as well as etiological aspects of neurodevelopmental disorders. Since cortical volume loss (Falkai et al, 2001; Selemon, 2001), inadequate and atypical social behavior, social withdrawal, and deficient cooperative play (DSM IV, American Psychiatric Association, 1994) are among the findings of patients in schizophrenia and autism, we propose the combination of neonatal cortical lesions with chronic cannabinoid administration during pubertal development as an appropriate animal model for studying the origin and neuronal correlates of impaired social functioning in neurodevelopmental disorders.

\section{ACKNOWLEDGEMENTS}

This study was supported by the DFG (SFB 517, TP A11).

\section{REFERENCES}

Adams PM, Barratt ES (1975). Effect of chronic marijuana administration of stages of primate sleep-wakefulness. Biol Psychiatry 10: 315-322.

American Psychiatric Association (1994). Diagnostic and Statistical Manual of Mental Disorders. American Psychiatric Press: Washington, DC. 
Anderson SW, Bechara A, Damasio H, Tranel D, Damasio AR (1999). Impairment of social and moral behavior related to early damage in human prefrontal cortex. Nat Neurosci 2: 1032-1037.

Arevalo C, de Miguel R, Hernandez-Tristan R (2001). Cannabinoid effects on anxiety-related behaviours and hypothalamic neurotransmitters. Pharmacol Biochem Behav 70: 123-131.

Arseneault L, Cannon M, Poulton R, Murray R, Caspi A, Moffitt TE (2002). Cannabis use in adolescence and risk for adult psychosis: longitudinal prospective study. BMJ 325: 1212-1213.

Arseneault L, Cannon M, Witton J, Murray RM (2004). Causal association between cannabis and psychosis: examination of the evidence. Br J Psychiatry 184: 110-117.

Badre D, Wagner AD (2004). Selection, integration, and conflict monitoring; assessing the nature and generality of prefrontal cognitive control mechanisms. Neuron 41: 473-487.

Baron-Cohen S, Ring HA, Wheelwright S, Bullmore ET, Brammer MJ, Simmons A et al (1999). Social intelligence in the normal and autistic brain: an fMRI study. Eur J Neurosci 11: 1891-1898.

Becker A, Grecksch G (2000). Social memory is impaired in neonatally ibotenic acid lesioned rats. Behav Brain Res 109: 137-140.

Becker A, Grecksch G, Bernstein H, Höllt V, Bogerts B (1999). Social behaviour in rats lesioned with ibotenic acid in the hippocampus: quantitative and qualitative analysis. Psychopharmacology 144: 333-338.

Benes FM, Taylor JB, Cunningham MC (2000). Convergence and plasticity of monoaminergic systems in the medial prefrontal cortex during the postnatal period: implications for the development of psychopathology. Cereb Cortex 10: 1014-1027.

Bennay M, Gernert M, Schwabe K, Enkel T, Koch M (2004). Neonatal medial prefrontal cortex lesion enhances the sensitivity of the mesoaccumbal dopamine system. Eur J Neurosci 19: $3277-3290$.

Blanchard RJ, McKittrick CR, Blanchard DC (2001). Animal models of social stress: effects on behavior and brain neurochemical systems. Physiol Behav 73: 261-271.

Brake WG, Flores G, Francis D, Meaney MJ, Srivastava LK, Gratton A (2000). Enhanced nucleus accumbens dopamine and plasma corticosterone stress responses in adult rats with neonatal excitotoxic lesions to the medial prefrontal cortex. Neuroscience 96: 687-695.

Cannizzaro C, Martire M, Cannizzaro E, Provenzano G, Gagliano M, Carollo A et al (2001). Long-lasting handling affects behavioural reactivity in adult rats of both sexes prenatally exposed to diazepam. Brain Res 904: 225-233.

Carr DB, Sesack SR (2000). Projections from the rat prefrontal cortex to the ventral tegmental area: target specificity in the synaptic associations with mesoaccumbens and mesocortical neurons. J Neurosci 20: 3864-3873.

Chambers RA, Taylor JR, Potenza MN (2003). Developmental neurocircuitry of motivation in adolescence: a critical period of addiction vulnerability. Am J Psychiatry 160: 1041-1052.

Cheer JF, Kendall DA, Marsden CA (2000). Cannabinoid receptors and reward in the rat: a conditioned place preference study. Psychopharmacology 151: 25-30.

Cromwell HC, Berridge KC (1996). Implementation of action sequences by a neostriatal site: a lesion mapping study of grooming syntax. J Neurosci 16: 3444-3458.

Czyrak A, Mackowiak M, Chocyk A, Fijal K, Wedzony K (2003). Role of glucocorticoids in the regulation of dopaminergic neurotransmission. Pol J Pharmacol 55: 667-674.

Daenen EW, Wolterink G, Gerrits MA, Van Ree JM (2002). The effects of neonatal lesions in the amygdala or ventral hippocampus on social behaviour later in life. Behav Brain Res 136: 571-582.

De Bellis MD, Keshavan MS, Beers SR, Hall J, Frustaci K, Masalehdan A et al (2001). Sex differences in brain maturation during childhood and adolescence. Cereb Cortex 11: 552-557.
De Bruin JP (1990). Social behaviour and the prefrontal cortex. Prog Brain Res 85: 485-497.

Ehrenreich H, Rinn T, Kunter HJ, Moeller MR, Poser W, Schilling $\mathrm{L}$ et al (1999). Specific attentional dysfunction in adults following early start of cannabis use. Psychopharmacology 142: 295-301.

Ellenbroek BA, Cools AR (2000). Animal models for the negative symptoms of schizophrenia. Behav Pharmacol 11: 223-233.

Eslinger PJ, Flaherty-Craig CV, Benton AL (2004). Developmental outcomes after early prefrontal cortex damage. Brain Cogn 55: 84-103.

Fagen RM (1981). Animal Play Behaviour. Oxford University Press: New York.

Falkai P, Vogeley K, Maier W (2001). Structural brain changes in patients with schizophrenic psychoses. From focal pathology to network disorder. Nervenarzt 72: 331-341.

Flores G, Wood GK, Liang J, Quirion R, Srivastava LK (1996). Enhanced amphetamine sensitivity and increased expression of dopamine D2 receptors in postpubertal rats after neonatal excitotoxic lesions of the medial prefrontal cortex. J Neurosci 16: $7366-7375$.

Fuster JM (2002). Frontal lobe and cognitive development. J Neurocytol 31: 373-385.

Goldberg JO, Schmidt LA (2001). Shyness, sociability, and social dysfunction in schizophrenia. Schizophr Res 48: 343-349.

Grace AA, Rosenkranz JA (2002). Regulation of conditioned responses of basolateral amygdala neurons. Physiol Behav 77: 489-493.

Grossman JB, Carter A, Volkmar FR (1997). Social behavior in autism. Ann NY Acad Sci 807: 440-454.

Hall W, Solowij N (1998). Adverse effects of cannabis. Lancet 352: 1611-1616.

Haller J, Varga B, Ledent C, Barna I, Freund TF (2004). Contextdependent effects of CB1 cannabinoid gene disruption on anxiety-like and social behaviour in mice. Eur J Neurosci 19: 1906-1912.

Jinks AL, McGregor IS (1997). Modulation of anxiety-related behaviours following lesions of the prelimbic or infralimbic cortex in the rat. Brain Res 772: 181-190.

Kelley AE, Domesick VB, Nauta WJ (1982). The amygdalostriatal projection in the rat - an anatomical study by anterograde and retrograde tracing methods. Neuroscience 7: 615-630.

Kolb B, Cioe J (2001). Cryoanesthesia on postnatal day 1, but not day 10, affects adult behavior and cortical morphology in rats. Brain Res Dev Brain Res 130: 9-14.

Kolb B, Holmes C, Whishaw IQ (1987). Recovery from early cortical lesions in rats. III. Neonatal removal of posterior parietal cortex has greater behavioral and anatomical effects than similar removals in adulthood. Behav Brain Res 26: 119-137.

Kolb B, Whishaw IQ (1985). Earlier is not always better: behavioral dysfunction and abnormal cerebral morphogenesis following neonatal cortical lesions in the rat. Behav Brain Res 17: 25-43.

Lamarque S, Taghzouti K, Simon H (2001). Chronic treatment with delta(9)-tetrahydrocannabinol enhances the locomotor response to amphetamine and heroin. Implications for vulnerability to drug addiction. Neuropharmacology 41: 118-129.

Levine S (2001). Primary social relationships influence the development of the hypothalamic-pituitary-adrenal axis in the rat. Physiol Behav 73: 255-260.

Lipska BK, Aultman JM, Verma A, Weinberger DR, Moghaddam B (2002a). Neonatal damage of the ventral hippocampus impairs working memory in the rat. Neuropsychopharmacology 27: 47-54.

Lipska BK, Halim ND, Segal PN, Weinberger DR (2002b). Effects of reversible inactivation of the neonatal ventral hippocampus on behavior in the adult rat. J Neurosci 22: 2835-2842.

Lipska BK, Swerdlow NR, Geyer MA, Jaskiw GE, Braff DL, Weinberger DR (1995). Neonatal excitotoxic hippocampal 
damage in rats causes post-pubertal changes in prepulse inhibition of startle and its disruption by apomorphine. Psychopharmacology 122: 35-43.

Luna B, Minshew NJ, Garver KE, Lazar NA, Thulborn KR, Eddy WF et al (2002). Neocortical system abnormalities in autism: an fMRI study of spatial working memory. Neurology 59: 834-840.

Manzanares J, Corchero J, Fuentes JA (1999). Opioid and cannabinoid receptor-mediated regulation of the increase in adrenocorticotropin hormone and corticosterone plasma concentrations induced by central administration of $\Delta^{9}$-tetrahydrocannabinol in rats. Brain Res 839: 173-179.

Marin S, Marco E, Biscaia M, Fernandez B, Rubio M, Guaza C et al (2003). Involvement of the kappa-opioid receptor in the anxiogenic-like effect of CP 55,940 in male rats. Pharmacol Biochem Behav 74: 649-656.

Matthews K, Robbins TW (2003). Early experience as a determinant of adult behavioural responses to reward: the effects of repeated maternal separation in the rat. Neurosci Biobehav Rev 27: 45-55.

McCormick CM, Kehoe P, Kovacs S (1998). Corticosterone release in response to repeated, short episodes of neonatal isolation: evidence of sensitization. Int J Dev Neurosci 16: 175-185.

McCormick CM, Kehoe P, Mallinson K, Cecchi L, Frye CA (2002). Neonatal isolation alters stress hormone and mesolimbic dopamine release in juvenile rats. Pharmacol Biochem Behav 73: 77-85.

Milad MR, Quirk GJ (2002). Neurons in medial prefrontal cortex signal memory for fear extinction. Nature 420: 70-74.

Moller P, Husby R (2000). The initial prodrome in schizophrenia: searching for naturalistic core dimensions of experience and behavior. Schizophr Bull 26: 217-232.

Mundy P (2003). Annotation: the neural basis of social impairments in autism: the role of the dorsal medial-frontal cortex and anterior cingulate system. J Child Psychol Psychiatry 44: 793-809.

Murillo-Rodriguez E, Sanchez-Alavez M, Navarro L, MartinezGonzalez D, Drucker-Colin R, Prospero-Garcia O (1998). Anandamide modulates sleep and memory in rats. Brain Res 812: $270-274$.

Navarro M, Rubio T, Rodriguez de Fonseca F (1994). Sexdimorphic psychomotor activation after perinatal exposure to $(-)-\Delta^{9}$-tetrahadrocannabinol. An ontogenic study in Wistar rats. Psychopharmacology 116: 414-422.

Newport DJ, Stowe ZN, Nemeroff CB (2002). Parental depression: animal models of an adverse life event. Am J Psychiatry 159: $1265-1283$.

Nunez JL, Kim BY, Juraska JM (1998). Neonatal cryoanesthesia affects the morphology of the visual cortex in the adult rat. Brain Res Dev Brain Res 111: 89-98.

Nunez JL, Koss WA, Juraska JM (2000). Hippocampal anatomy and water maze performance are affected by neonatal cryoanesthesia in rats of both sexes. Horm Behav 37: 169-178.

Pani L, Porcella A, Gessa GL (2000). The role of stress in the pathophysiology of the dopaminergic system. Mol Psychiatry 5: 14-21.

Panksepp J, Normansell L, Cox JF, Siviy SM (1994). Effects of neonatal decortication on the social play of juvenile rats. Physiol Behav 56: 429-443.

Pellis SM, Castaneda E, McKenna M, Tran-Nguyen LTL, Wishaw IQ (1993). The role of the striatum in organizing sequences of play fighting in neonatally dopamine depleted rats. Neurosci Lett 158: $13-15$.

Pellis SM, Field EF, Smith LK, Pellis VC (1997). Multiple differences in the play fighting of male and female rats. Implications for the causes and functions of play. Neurosci Biobehav Rev 21: 105-120.

Pellis SM, McKenna M (1995). What do rats find rewarding in play fighting? An analysis using drug-induced non play-playful partners. Behav Brain Res 68: 65-73.
Pellis SM, Pellis VC (1997). The prejuvenile onset of play fighting in laboratory rats (Rattus norvegicus). Dev Psychobiol 31: 193-205.

Pellis SM, Pellis VC (1998). Play fighting of rats in comparative perspective: a schema for neurobehavioral analyses. Neurosci Biobehav Rev 23: 87-101.

Pellis SM, Pellis VC, Wishaw IQ (1992). The role of the cortex in play fighting by rats: developmental and evolutionary implications. Brain Behav Evol 39: 270-284.

Pistis M, Perra S, Pillolla G, Melis M, Muntoni AL, Gessa GL (2004). Adolescent exposure to cannabinoids induces longlasting changes in the response to drugs of abuse of rat midbrain dopamine neurons. Biol Psychiatry 56: 86-94.

Pope HG, Gruber AJ, Hudson JI, Cohane G, Huestis MA, YurgelunTodd D (2003). Early-onset cannabis use and cognitive deficits: what is the nature of the association? Drug Alcohol Depend 69: 303-310.

Rangel A, Gonzalez LE, Villarroel V, Hernandez L (2003). Anxiolysis followed by anxiogenesis relates to coping and corticosterone after medial prefrontal cortical damage in rats. Brain Res 992: 96-103.

Robertson BJ, Boon F, Cain DP, Vanderwolf CH (1999). Behavioral effects of anti-muscarinic, anti-serotonergic, and anti-NMDA treatments: hippocampal and neocortical slow wave electrophysiology predict the effects on grooming in the rat. Brain Res 838: $234-240$.

Rodriguez de Fonseca F, Ramos JA, Bonnin A, Fernandez-Ruiz JJ (1993). Presence of cannabinoid binding sites in the brain from early postnatal ages. Neuroreport 4: 135-138.

Rosenkranz JA, Grace AA (2001). Dopamine attenuates prefrontal cortical suppression of sensory inputs to the basolateral amygdala of rats. J Neurosci 21: 4090-4103.

Russell TA, Rubia K, Bullmore ET, Soni W, Suckling J, Brammer MJ et al (2000). Exploring the social brain in schizophrenia: left prefrontal underactivation during mental state attribution. Am J Psychiatry 157: 2040-2042.

Sams-Dodd F, Lipska BK, Weinberger DR (1997). Neonatal lesions of the rat ventral hippocampus result in hyperlocomotion and deficits in social behaviour in adulthood. Psychopharmacology 132: 303-310.

Santucci V, Storme JJ, Soubrie P, Le Fur G (1996). Arousalenhancing properties of the CB1 cannabinoid receptor antagonist SR 141716A in rats as assessed by electroencephalographic spectral and sleep-waking cycle analysis. Life Sci 58: L103-L110. Schmidt M, Oitzl MS, Levine S, de Kloet ER (2002). The HPA system during the postnatal development of CD1 mice and the effects of maternal deprivation. Brain Res Dev Brain Res 139: 39-49.

Schneider M, Koch M (2003). Chronic pubertal, but not adult chronic cannabinoid treatment impairs sensorimotor gating, recognition memory and the performance in a progressive ratio task in adult rats. Neuropsychopharmacology 28: 1760-1769.

Schwabe K, Enkel T, Klein S, Schutte M, Koch M (2004). Effects of neonatal lesions of the medial prefrontal cortex on adult rat behaviour. Behav Brain Res 153: 21-34.

Selemon LD (2001). Regionally diverse cortical pathology in schizophrenia: clues to the etiology of the disease. Schizophr Bull 27: 349-377.

Serafim AP, Felicio LF (2001). Dopaminergic modulation of grooming behavior in virgin and pregnant rats. Braz J Med Biol Res 34: 1465-1470.

Sherwood NM, Timiras PS (1970). A Stereotaxic Atlas of the Developing Rat Brain. University of California Press: Berkeley, LA, London.

Sieber B (1982). Influence of hashish extract on the social behaviour of encountering male baboons (Papio c. anubis). Pharmacol Biochem Behav 17: 209-216.

Sieber B, Frischknecht HR, Waser PG (1980). Behavioral effects of hashish in mice. I. Social interactions and nest-building behavior of males. Psychopharmacology 70: 149-154. 
Spear LP (2000). The adolescent brain and age-related behavioral manifestations. Neurosci Biobehav Rev 24: 417-463.

Stiglick A, Kalant H (1985). Residual effects of chronic cannabis treatment on behavior in mature rats. Psychopharmacology 85: 436-439.

Tang AC, Reeb BC, Romeo RD, McEwen BS (2003). Modification of social memory, hypothalamic-pituitary-adrenal axis, and brain asymmetry by neonatal novelty exposure. J Neurosci 23: 8254-8260.

Van den Berg CL, Pijlman FT, Koning HA, Diergaarde L, Van Ree JM, Spruijt BM (1999). Isolation changes the incentive value of sucrose and social behaviour in juvenile and adult rats. Behav Brain Res 106: 133-142.

van Os J, Bak M, Hanssen M, Bijl RV, de Graaf R, Verdoux H (2002). Cannabis use and psychosis: a longitudinal populationbased study. Am J Epidemiol 156: 319-327.

Van Ree JM, Niesink RJ, Nir I (1984). Delta 1-tetrahydrocannabinol but not cannabidiol reduces contact and aggressive behavior of rats tested in dyadic encounters. Psychopharmaco$\log y$ 84: 561-565.

Vanderschuren LJ, Niesink RJ, Spruijt BM, Van Ree JM (1995). Effects of morphine on different aspects of social play in juvenile rats. Psychopharmacology 117: 225-231.
Vanderschuren LJ, Niesink RJ, Van Ree JM (1997). The neurobiology of social play behavior in rats. Neurosci Biobehav Rev 21: 309-326.

Vanderwolf CH, Kolb B, Cooley RK (1978). Behavior of the rat after removal of the neocortex and hippocampal formation. J Comp Physiol Psychol 92: 156-175.

Varlinskaya EI, Spear LP (2002). Acute effects of ethanol on social behavior of adolescent and adult rats: role of familiarity of the test situation. Alcohol Clin Exp Res 26: 1502-1511.

Waterhouse L, Fein D, Modahl C (1996). Neurofunctional mechanisms in autism. Psychol Rev 103: 457-489.

Weinberger DR, Lipska BK (1995). Cortical maldevelopment, antipsychotic drugs, and schizophrenia: a search for common ground. Schizophr Res 16: 87-110.

Wolterink G, Daenen LEWPM, Dubbeldam S, Gerrits MAFM, van Rijn R, Kruse CG et al (2001). Early amygdala damage in the rat as a model for neurodevelopmental psychopathological disorders. Eur Neuropsychopharmacol 11: 51-59.

Wood JN (2003). Social cognition and the prefrontal cortex. Behav Cogn Neurosci Rev 2: 97-114.

Zammit S, Allebeck P, Andreasson S, Lundberg I, Lewis G (2002). Self reported cannabis use as a risk factor for schizophrenia in Swedish conscripts of 1969: historical cohort study. BMJ 325: 1199. 